\title{
Effects of post partum administration of ketoprofen on sow health and piglet growth
}

\section{Viitasaari, Elina}

2013

Viitasaari , E , Hänninen , L , Heinonen, M , Raekallio , M , Orro , T , Peltoniemi , O \& Valros , A 2013 , ' Effects of post partum administration of ketoprofen on sow health and piglet growth ' , The Veterinary Journal , vol. 198 , no. 1 , pp. 153-157 . https://doi.org/10.1016/j.tvjl.2013.06.013

http://hdl.handle.net/10138/42727

https://doi.org/10.1016/j.tvjl.2013.06.013

publishedVersion

Downloaded from Helda, University of Helsinki institutional repository.

This is an electronic reprint of the original article.

This reprint may differ from the original in pagination and typographic detail.

Please cite the original version. 


\title{
Effects of post-partum administration of ketoprofen on sow health and piglet growth
}

\author{
Elina Viitasaari ${ }^{\mathrm{a}, *}$, Laura Hänninen ${ }^{\mathrm{a}}$, Mari Heinonen ${ }^{\mathrm{a}}$, Marja Raekallio ${ }^{\mathrm{b}}$, Toomas Orro ${ }^{\mathrm{c}}$, Olli Peltoniemi ${ }^{\mathrm{a}}$, \\ Anna Valros ${ }^{\mathrm{a}}$ \\ ${ }^{a}$ Department of Production Animal Medicine, P.O. Box 57, University of Helsinki, Helsinki 00014, Finland \\ ${ }^{\mathrm{b}}$ Department of Equine and Small Animal Medicine, P.O. Box 57, University of Helsinki, Helsinki 00014, Finland \\ ${ }^{\mathrm{c}}$ Department of Animal Health and Environment, Institute of Veterinary Medicine and Animal Science, Estonian University of Life Sciences, Tartu 51014, Estonia
}

\section{A R T I C L E I N F O}

\section{Article history:}

Accepted 18 June 2013

Available online $\mathrm{xxxx}$

\section{Keywords:}

Sow

Farrowing

Ketoprofen

\begin{abstract}
A B S T R A C T
The effect of the non-steroidal anti-inflammatory drug ketoprofen on the post farrowing phase of sows was studied in a randomized, blinded, placebo-controlled trial. Ketoprofen $(3 \mathrm{mg} / \mathrm{kg}$ ) was administered intramuscularly to 20 healthy sows for 3 days post-partum (p.p.). The control group $(n=20)$ received a saline placebo. Backfat, number of days of constipation and days before feed refusal were measured. Body condition (BCS) and shoulder sores were scored for 1 week p.p. Changes in BCS, backfat and shoulder sore scores were analysed with ANOVA. Blood was collected on days $-1,0,5$ and 14 with respect to medication. Aspartate aminotransferase (AST), creatinine kinase (CK), haptoglobin and serum amyloid A (SAA) were quantified and analysed with a Mann-Whitney $U$ test.

BCS and backfat decreased less following ketoprofen administration than with the placebo $(-0.08 \pm 0.2$ vs. $-0.8 \pm 0.2,1.0 \pm 0.8 \mathrm{~mm}$ vs. $-2.0 \pm 0.9 \mathrm{~mm}$, respectively; $P<0.05$ for both) during the first 2 weeks of lactation. The shoulder sore score deterioration was milder during days 4-6 p.p. with ketoprofen than placebo $(P<0.05)$. Duration of constipation was shorter with ketoprofen than placebo $(5.5 \pm 0.3$ vs. $6.4 \pm 0.3$ days p.p.; $P<0.05$ ). Incidences of feed refusal occurred later in the ketoprofen group than in the placebos ( $9.6 \pm 0.9$ vs. $3.8 \pm 0.8$ days p.p.; $P<0.05$ ). AST and SAA values were higher after ketoprofen administration than placebo on day 5 p.p. $(P<0.05)$. It was concluded that ketoprofen appeared to benefit sows during the first 2 weeks post farrowing, but caused some tissue irritation.
\end{abstract}

() 2013 Elsevier Ltd. All rights reserved.

\section{Introduction}

No information appears to be available in the literature on pain associated with farrowing and early lactation of sows, or on the effect of pain on health and body mass. Feed refusal has been shown to be a component of pain and sickness behaviour (McGlone et al., 1993; for review, see Weary et al., 2008) and led to deterioration in body condition. This can accelerate after 2 weeks postpartum (p.p.) (Valros et al., 2003). Sows with poor body condition score (BCS) are at increased risk of developing decubital shoulder sores (Tantasuparuk et al., 2001; Bonde et al., 2004; Maes et al., 2004). Gorecki et al. (2010) reported that human patients with a similar type of pressure ulcer experienced pain, which has not been evaluated in pigs.

Low bodyweight (BW) has been shown to indicate poor reproductive success, and is a major reason for culling sows (Tantasuparuk et al., 2001; Maes et al., 2004; Anil et al., 2008). It is therefore important to maintain sow BW during lactation. Feed

\footnotetext{
* Corresponding author. Tel.: +358 504156657.

E-mail address: elina.viitasaari@helsinki.fi (E. Viitasaari).
}

refusal can lead not only to poor BW but also to constipation, which is a major cause of abdominal pain in children (LoeningBaucke and Swidsinski, 2007), and may also cause pain in sows. Oliviero et al. (2010) reported that severe constipation is linked to prolonged farrowing. Stressful delivery also delays breast filling during early lactation, contributing to nursing difficulties in women (Chen et al., 1998). Piglet growth depends on nursing (Valros et al., 2002) and problems in lactation consequently affect piglets.

Parturition can cause external symptoms of malaise with tissue breakdown and inflammation. Tissue damage can be detected as increased serum aspartate aminotransferase (AST) and creatinine kinase (CK) activity, which are both released from damaged muscle cells (Nogueira et al., 2000). Acute phase proteins (APPs), such as haptoglobin ( $\mathrm{Hp}$ ) and serum amyloid A (SAA) concentrations increase during the inflammatory processes (Chen et al., 2003; Heinonen et al., 2010), and during the puerperium period (Verheyen et al., 2007; Papadopoulos et al., 2009).

Ketoprofen is a non-steroidal anti-inflammatory drug (NSAID), and has been approved for use in pigs (EMEA, 1996). It has antipyretic, anti-inflammatory and analgesic effects, and the 
recommended dose is $3 \mathrm{mg} / \mathrm{kg}$ BW (EMEA, 1996). Ketoprofen is absorbed well and reaches peak plasma concentration rapidly after intramuscular (IM) administration (Raekallio et al., 2008; Fosse et al., 2011a). Ketoprofen products for veterinary use are racemic compounds but it is the $\mathrm{S}(+)$ isomer that is predominant in pigs after administration (Neirinckx et al., 2011; Mustonen et al., 2012). Ketoprofen is effective for treating pain in lame sows (Mustonen et al., 2011) and sows with respiratory infections (Swinkels et al., 1994).

Field observations suggest that sows that have farrowed within $24 \mathrm{~h}$ benefit from the use of analgesics. Our study investigated the effect of post-partum (p.p.) administration of ketoprofen on sow feeding, BCS, appearance of shoulder sores and duration of constipation. In addition, we studied the effect of ketoprofen on AST, CK, SAA and Hp. Our hypothesis was that when administered p.p. to sows ketoprofen helps maintain good body condition, reduces risk of shoulder sores, decreases duration of constipation, reduces inflammation and improves piglet performance.

\section{Materials and methods}

The experimental procedures were approved by the National Animal Experiment Board (ESAVI-2010-09747/Ym-23, PH22A) and FIMEA, the Finnish Medicines Agency (Vetkl-nro 03/10).

\section{Animals and housing}

We performed a double blind, placebo-controlled clinical field trial on 40 sows in a commercial piglet producing farm in Western Finland. The sows were moved to farrowing crates approximately 7 days prior to expected farrowing. The crates had fully slatted floors with a heat plate and a heat lamp for the piglets. The sows received a handful of fresh straw every day. Lactating sows were given a commercial liquid feed five times daily, with an energy content starting from 17.6 MJ on day 1 of lactation, and increasing up to $128.0 \mathrm{MJ}$ by day 18 . Water was available freely from a water nipple. Farrowings were monitored during piggery working hours (from 06:00 to 15:005 h) and assistance was provided when needed during working hours.

When all piglets had been born and placentas expelled, the piglets were isolated from their mothers by a low fence either for approximately $1.5 \mathrm{~h}$ as soon as farrowing was considered over, or in the following morning at 06:00 $\mathrm{h}$ if farrowing had taken place at night. During that separation period the sow received an injection of 7$10 \mathrm{IU}$ oxytocin to improve colostrum excretion. Litters were adjusted during the first day of life by merging equal sized piglets into a litter. A routine health check was performed daily by the carers from farrowing to weaning. Any obvious signs of disease or injury were recorded.

\section{Medication}

The sows were randomly allocated to two groups both containing 20 sows. The treatment group (KET) received $3 \mathrm{mg} / \mathrm{kg}$ ketoprofen (Ketovet $100 \mathrm{mg} / \mathrm{mL}$, Richter Pharma) IM and the placebo group (PLAC) received an equal volume of isotonic saline. The first administration was given when the piglets were isolated by the fence, and was repeated once daily for a further 2 consecutive days.

\section{Body condition score, backfat thickness and assessment of shoulder sores}

BCS was assessed and backfat thickness measured for each sow at farrowing, on day 14 p.p. and at weaning (average 23 days). A scale of $1-5$ ( $1=$ thin, $2=$ decent, $3=$ good, 4 = very good, and $5=$ fat) (Bonde et al., 2004) was used to gauge BCS. Backfat was measured with a digital backfat indicator (Renco Leanometer) at $70 \mathrm{~mm}$ behind the ribcage and from the spine. Shoulders were scored daily from day 0 to day 6 p.p. The severity of the shoulder lesions was classified on a scale of $0-3$ according to Rolandsdotter et al. (2009); $0=$ no mark of lesion, $1=$ redness on the skin, 2 = redness of the skin and a small wound, 3 = deep and large wound, surrounding skin darkened.

\section{Feeding behaviour and constipation}

Each trough was checked every morning from farrowing to weaning. Feed refusal was recorded when the sow had left approximately half or more of her feed in the trough. The first day of feed refusal was recorded. Faeces of all sows were assessed daily from day 0 to day 7 p.p. and scored according to Oliviero et al. (2010): $0=$ absence of faeces, $1=$ dry, small number of unformed and pelleted faeces, 2 = pelleted but shaped dry faeces, 3 = normal, firm and soft faeces, $4=$ normal but not firm soft faeces, 5 = watery, unformed faeces. Faeces scores of 0 and 1 indicated constipation.

\section{Piglet performance}

Piglets were weighed by litter on the day of farrowing (day 0) after litter adjustment, on day 14 and at weaning. The number of piglets was recorded at each weighing and average daily weight gains (ADG) were calculated.

\section{Blood sampling}

Using an $18 \mathrm{G}$ needle blood (10 mL, uncoated tubes) was collected via the saphenous, coccygeal or medial auricular veins from each sow for analysis of AST, CK, SAA and Hp on four occasions: 1 or 2 days prior to expected farrowing, at day 0 (after farrowing) and at days 5 and 14 p.p. The serum was separated by centrifugation ( $1900 \mathrm{~g}$ for $15 \mathrm{~min}$ ), and stored at $-20^{\circ} \mathrm{C}$ until analysed.

\section{Laboratory analyses}

Serum Hp was analysed using a haemoglobin-binding assay developed for cows (Makimura and Suzuki, 1982) with modifications, in which tetramethylbenzidine was selected as a substrate (Alsemgeest et al., 1994) and $5 \mu \mathrm{g}$ of sample volume were used (originally $20 \mu \mathrm{g}$ ). The assay was adapted for microtitration plates and optical densities (OD) of the wells were read at $450 \mathrm{~nm}$ using a spectrophotometer (Multiskan MS, Labsystems). Pooled and lyophilized aliquots of porcine acute phase serum were used to create standard curves by serial dilutions. The standard curve range was $254-4060 \mathrm{mg} / \mathrm{L}$. The assay was calibrated using a porcine serum sample of known Hp concentration provided by the European Commission Concerted Action Project (number QLK5-CT-1999-0153).

Serum concentrations of SAA were measured using a commercially available ELISA kit (Phase SAA Assay, Tridelta Development), according to the manufacturer's instructions for pigs. Initially a serum dilution of 1:500 was used for all samples. The activities of CK and AST were assessed using a clinical chemistry analyser (Konelab 30i, ThermoFisher Scientific).

\section{Statistics}

Changes in backfat and BCS were calculated between farrowing (day 0) and day $14(0-14)$, day 14 and weaning (14-WEA), and from farrowing to weaning (0WEA). Shoulder sore scores were calculated separately for changes between day 0 and all 5 consecutive days. Sows were classified according to their parity as belonging to either parity 2-5 $(n=26)$ or parity 6-9 $(n=14)$. ADG was also calculated 0 14, 14-WEA and 0-WEA.

The effect of treatment (KET and PLAC) and parity on ADG and changes in BCS, backfat and shoulder sore score, total days of constipation and first appearance (days p.p.) of feed refusal, were analysed using a two-way ANOVA. Fixed factors were treatment, parity and their interaction. Total piglet mass growth was used as a covariate for the analysis of changes in BCS and backfat, and total piglet mass growth $0-14$ was used as a covariate in the models analysing the number of constipation days and the first day of feed refusal. Backfat on day 0 was used as a covariate in the models for shoulder sore score change, and BCS on day 0 in the model for analysing treatment effect on ADG.

The normality and homogeneity assumptions of the models were checked with a normal probability plot of residuals and scatter plot residuals against fitted values. Residuals in blood parameters failed to conform to a normal distribution and a Mann-Whitney $U$ test was used to analyse the overall effect of treatment on blood parameters, separately for each sampling day, and for both parity classes. All the ANOVA results are presented as model estimates and standard errors of means (mean \pm SEM), and results for non-parametric Mann-Whitney $U$ tests as medians (range). The upper limit for the statistically significant effect was set to $P<0.05$. All statistical analyses were conducted using PASW Statistics 18.0.1.

\section{Results}

Changes in BCS between sampling points was smaller in the KET sows than in the PLAC sows in period 0-14 (Fig. 1) but not at any other interval. However, there was an interaction between treatment and parity $(P=0.002)$. No difference was detected in parity 2-5 sows for BCS loss between treatments, but parity 6-9 KET sows had lower losses in BCS 0-14 than PLAC sows from the same parity group (Fig. 2). KET sows gained thickness in backfat, but PLAC sows lost thickness (Fig. 3). Interaction between treatment and parity showed no effect $(P=0.08)$ for changes in backfat $0-14$.

Treatment affected shoulder sore score changes between days $0-3$ and $0-4(P=0.006$ for both $)$ and $0-5(P=0.02$, Fig. 4$)$. Treat- 


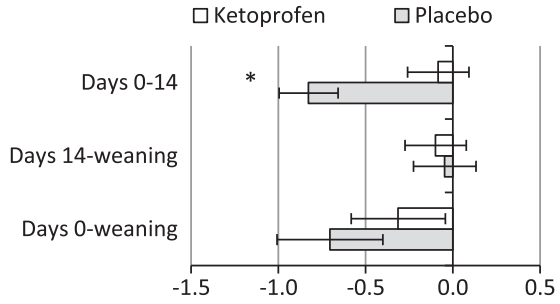

Fig. 1. Changes between sampling points in body condition score $(1=$ thin, $5=$ fat $)$ during the first 2 weeks after farrowing (days 0-14) from day 14 to weaning and the whole lactation period (days 0 -weaning) in sows (parity 2-9) receiving either ketoprofen $(n=20)$ or a placebo $(n=20)$ intramuscularly for 3 consecutive days post farrowing. ${ }^{*} P<0.05$.

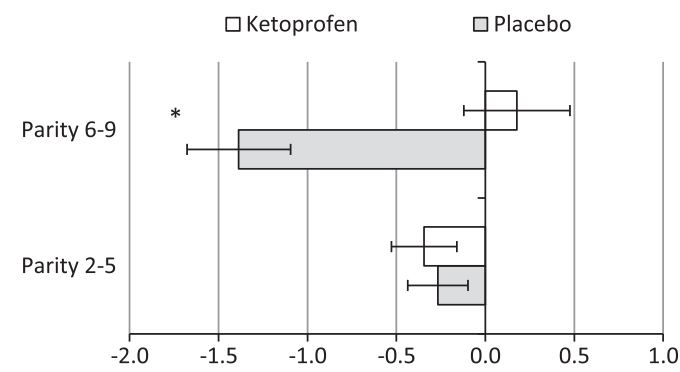

Fig. 2. Change in body condition score during the first 2 weeks after farrowing (day $0-14)$ in sows in parity groups $2-5$ and $6-9$ receiving either ketoprofen $(n=20)$ or a placebo $(n=20)$ intramuscularly for 3 consecutive days post farrowing. ${ }^{*} P<0.05$.

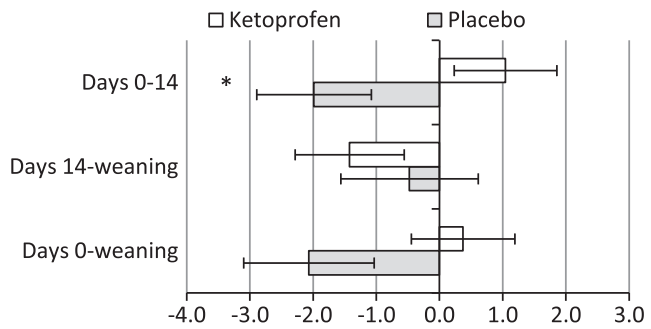

Fig. 3. Change in backfat ( $\mathrm{mm}$ ) during the first 2 weeks after farrowing (days 0-14) from day 14 to weaning and the whole lactation period (days 0-weaning) in sows (parity 2-9) receiving either ketoprofen $(n=20)$ or a placebo $(n=20)$ intramuscularly for 3 consecutive days post farrowing. ${ }^{*} P<0.05$

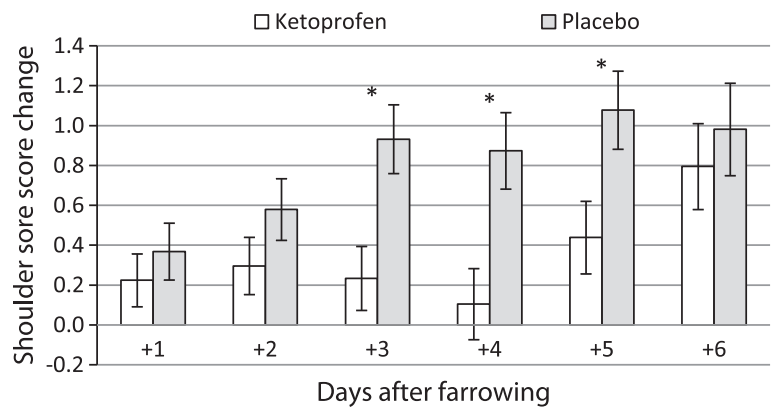

Fig. 4. Change in shoulder sore score $(0=$ healthy, $3=$ severe wound $)$ during the first week after farrowing (day 0 ) in sows (parity 2-9) receiving either ketoprofen $(n=20)$ or a placebo $(n=20)$ intramuscularly for 3 consecutive days post farrowing. ${ }^{*} P<0.05$.

ment by parity interaction pointed to an effect on shoulder sore score changes between days $0-5(P=0.045)$ with parity $6-9$ sows characterised by higher change in scores in the PLAC group than in the KET group ( $1.4 \pm 0.3$ vs. $0.2 \pm 0.3$ respectively, $P=0.01$ ).
All sows were affected by constipation for at least 1 day after farrowing. KET sows had fewer days of constipation than PLAC sows. Eleven sows (5 KET and 6 PLAC) refused feed during lactation and this was significantly later in KET compared to PLAC sows (Fig. 5). No KET sow showed feed refusal during treatment but two PLAC sows refused feed during the treatment period.

No treatment effect was detected for ADG 0-14 $(P=0.3)$, 14-WEA $(P=0.6)$ and $0-$ WEA $(P=0.4)$ sows and there was no interaction between treatment and parity $(P=0.06)$. Parity $2-5$ sows did not differ for KET and PLAC in ADG 0-14 (231 \pm 16 vs. $254 \pm 17 \mathrm{~g} /$ day), and neither did parity 6-9 sows between KET and PLAC groups $(285 \pm 26$ vs. $220 \pm 30 \mathrm{~g} /$ day respectively, $P=0.09$ ).

No treatment effect was found for serum CK activity across all parities at any sampling point (Table 1 ). Serum CK differed between treatments on day 5 p.p. in parity $2-5$ sows (KET 1085.0 (259-2596) U/L vs. PLAC 508.0 (343-802) U/L, $P=0.02$, respectively), but not at other sampling points. There were no differences in serum CK at any sampling point for parity 6-9 sows. A treatment effect was found for AST on day 5 p.p. (Table 1). Treatment differed for parity 2-5 sows on day 5 p.p. (KET 37.0 [15-244] U/L vs. PLAC 24 [14-29] U/L, $P=0.008$ ), but not for parity 6-9 sows.

Treatment had no overall effect on serum Hp concentration at any sampling point (Table 1 ). KET and PLAC differed only for parity $2-5$ sows on day -1 (2.0(1.6-2.6) g/L vs. 2.2(1.6-3.9) g/L respectively, $P=0.04)$. No other sampling point in either parity group indicated any difference. Treatment affected serum SAA concentration only on day 5 p.p. (Table 1 ). Sows in parity 2-5 were not differentially affected by treatments for SAA concentrations at any sampling point, but parity 6-9 sows differed on day 5 p.p. (KET 31.2 [12.4-490.6] mg/L, PLAC 16.6 [8.1-24.1] mg/L, $P=0.04)$.

\section{Discussion}

In accordance with our hypothesis, sows treated with ketoprofen maintained their body condition and back fat better during lactation and consequently suffered from shoulder sores later after farrowing than control sows. However, the ketoprofen effect was different between parities, with parity 6-9 sows benefitting from the ketoprofen treatment most, as their body condition deteriorated least.

Ketoprofen given p.p. supported the maintenance of a healthy state of body mass for the first 2 weeks of lactation; it also helped maintain BCS but with a gain in backfat thickness. The different treatment effects on BCS and backfat may reflect that backfat is not well correlated with BCS (Maes et al., 2004). Our assessment of BCS was visual and did not measure actual fat layer thickness, but other aspects such as muscle mass (Maes et al., 2004). Treat-

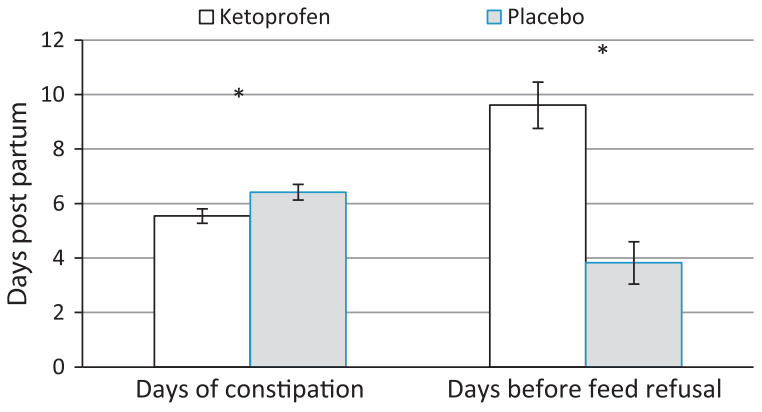

Fig. 5. Number of days of constipation and days prior to symptoms of 'feed refusal' $(n=11)$ in sows (parity $2-9)$ receiving ketoprofen $(n=20)$ or a placebo $(n=20)$ intramuscularly for 3 consecutive days post farrowing. ${ }^{*} P<0.05$ 


\section{Table 1}

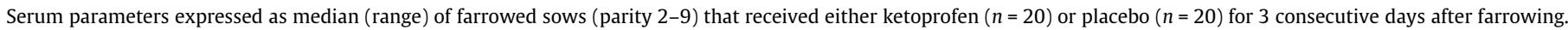
Serum was collected on days $-1,0,5$ and 14 with respect to farrowing.

\begin{tabular}{|c|c|c|c|c|c|c|c|c|}
\hline \multirow[t]{2}{*}{ Parameter } & \multicolumn{2}{|c|}{ Day -1 } & \multicolumn{2}{|c|}{ Day 0} & \multicolumn{2}{|c|}{ Day 5} & \multicolumn{2}{|c|}{ Day 14} \\
\hline & Ketoprofen & Placebo & Ketoprofen & Placebo & Ketoprofen & Placebo & Ketoprofen & Placebo \\
\hline Aspartate aminotransferase (U/L) & $21.0(10-670)$ & $22.0(12-53)$ & $47.0(22-121)$ & $40.0(22-73)$ & $30.0(12-244)^{*}$ & $24.0(14-38)^{*}$ & $21.0(14-77)$ & $23.0(13-36)$ \\
\hline Creatinine kinase $(\mathrm{U} / \mathrm{L})$ & $\begin{array}{c}448.0 \\
(232-2981)\end{array}$ & $\begin{array}{c}562.0 \\
(258-2241)\end{array}$ & $\begin{array}{c}1119.0 \\
(229-5972)\end{array}$ & $\begin{array}{c}866.0 \\
(343-7685)\end{array}$ & $\begin{array}{c}911.0 \\
(259-2596)\end{array}$ & $\begin{array}{c}489.0 \\
(218-1492)\end{array}$ & $\begin{array}{c}447.0 \\
(162-5293)\end{array}$ & $\begin{array}{c}593.0 \\
(197-1440)\end{array}$ \\
\hline Haptoglobin (g/L) & $2.0(0.8-2.6)$ & $2.1(1.5-3.9)$ & $2.3(0.8-2.8)$ & $2.1(1.7-3.7)$ & $3.0(1.1-3.6)$ & $2.4(2.1-3.2)$ & $2.5(1.0-4.0)$ & $2.0(1.7-3.4)$ \\
\hline Serum amyloid $\mathrm{A}(\mathrm{mg} / \mathrm{L})$ & $\begin{array}{c}11.0 \\
(1.7-56.1)\end{array}$ & $\begin{array}{c}10.1 \\
(3.6-1063)\end{array}$ & $\begin{array}{c}109.5 \\
(11.6-385.6)\end{array}$ & $\begin{array}{c}62.8 \\
(29.6-373.0)\end{array}$ & $\begin{array}{c}40.7 \\
(12.4-490.6)^{*}\end{array}$ & $\begin{array}{c}22.9 \\
(8.1-176.4)^{*}\end{array}$ & $\begin{array}{c}12.9 \\
(4.7-306.7)\end{array}$ & $\begin{array}{c}11.0 \\
(4.5-67.2)\end{array}$ \\
\hline
\end{tabular}

Significant difference between effect of ketoprofen and placebo at $P<0.05$.

ment effects lasted only for 2 weeks after farrowing and since no effect was recorded during the latter half of lactation, the benefit of ketoprofen on sow body condition appears limited. However the emergence of shoulder sores is unsurprisingly linked to poor cushioning over the bony prominences (Bouten et al., 2003). Ketoprofen treatment delayed shoulder sore appearance by a few days, presumably as a consequence of a thicker fat layer and so severe pressure ulcers appeared later. It is possible that we failed to observe subcutaneous chronic soft tissue damage (Jensen, 2009) and we may therefore have underestimated the severity of shoulder sores.

Higher parity sows in our study may have benefited from ketoprofen treatment because of subclinical conditions, such as histopathological changes in their mammary glands (Baer and Bilkei, 2005), which would have played an important role in reduced nursing behaviour, udder massage and milk yield (Auldist et al., 2000; Guillemet et al., 2007). The animals may also have been affected by undetected discomfort, such as orthopaedic pain (Heinonen et al., 2006; Mustonen et al., 2011), or subclinical subcutaneous chronic soft tissue damage (Jensen, 2009). Nevertheless, we found that ketoprofen had no significant effect on piglet weight gain, in agreement with a study by Mainau et al. (2012) who also reported no effect on piglet weight gain using another NSAID, meloxicam. In our study the parity 6-9 group was smaller than parity 2-5 group and the different effects in aged sows require further investigation.

An absence of refused feed and shorter duration of constipation during ketoprofen treatment supported the concept of good health in early lactation. Later incidences of feed refusal following ketoprofen use appeared after the action of the NSAID had waned and probably arose for reasons other than farrowing and early lactation pain. The duration of constipation was shorter with ketoprofen than with the placebo across all parities. Ease in passing faeces may promote health of these sows due to the diminished risk of excessive bacterial growth in the large intestine and translocation that can lead to endotoxemia (Khalif et al., 2005).

Parturition itself increases serum AST and CK activities (Nogueira et al., 2000; Nathwani et al., 2005). AST increased with ketoprofen use across all parities on day 5 p.p. and CK for parity 2-5 sows on day 5 p.p. Increase in these enzymes was most likely due to local tissue irritation caused by the ketoprofen injections as IM ketoprofen has been shown to increase plasma CK activity in cattle (Pyörälä et al., 1999; Nathwani et al., 2005; Verheyen et al., 2007) due to muscle cell degradation. Irritation appeared temporary, and by day 14 p.p. no difference was evident. As the oral administration of ketoprofen causes no injection site tissue irritation and is well absorbed (Raekallio et al., 2008; Fosse et al., 2011b; Mustonen, 2011), this could be a useful alternative route to use.

Concentrations of $\mathrm{Hp}$ indicate overall health status (Chen et al., 2003; Oravainen et al., 2006) but in the present study the APP did not seem to react to repetitive ketoprofen injections. Despite an increase in SAA after parturition (Papadopoulos et al., 2009) we noticed that parity 6-9 sows reacted more strongly to ketoprofen injections and the SAA levels were higher on day 5 p.p. but did not differ on other days from control sows, and so we may conclude that tissue irritation seemed to be transient. Elderly people have an altered inflammatory response that is seen as a stronger reaction in C-reactive protein to inflammatory stimuli (Krabbe et al., 2001) and this was reflected in our findings.

\section{Conclusions}

Ketoprofen supported good body condition in older sows during the first 2 weeks of lactation. The sows on the NSAID maintained their BCS and back fat better than untreated control sows. Further studies are needed to investigate painful conditions affecting old sows and to identify those individual animals that may benefit from ketoprofen treatment.

\section{Conflict of interest statement}

Fieldwork and data analyses were funded by Orion Pharmos, the Finnish Veterinary Foundation and the Oiva Kuusisto Foundation. Medications were donated by pharmaceutical company Vetcare. None of the authors has any financial or personal relationships that could inappropriately influence or bias the content of the paper.

\section{Acknowledgements}

We thank our experimental piggery for invaluable co-operation. Assistant Sini Niemelä is thanked for help with the data collection and Merja Pöytäkangas for the muscle enzyme analysis.

\section{References}

Alsemgeest, S.P.M., Kalsbeek, H.C., Wensing, T., Koeman, J.P., van Ederen, A.M. Gruys, E., 1994. Concentrations of serum amyloid-A (SAA) and haptoglobin (Hp) as parameters of inflammatory diseases in cattle. The Veterinary Quarterly 16 21-23.

Auldist, D.E., Carlson, D., Morrish, L., Wakeford, C.M., King, R.H., 2000. The influence of suckling interval on milk production of sows. Journal of Animal Science 78, 2026-2031.

Anil, S.S., Anil, L., Deen, J., 2008. Analysis of periparturient risk factors affecting sow longevity in breeding herds. Canadian Journal of Animal Science 88, 381-389.

Baer, C., Bilkei, G., 2005. Ultrasonographic and gross pathological findings in the mammary glands of weaned sows having suffered recidiving mastitis metritis agalactia. Reproduction in Domestic Animals 40, 544-547.

Bonde, M., Rousing. T. Badsbergb, J.H., Sørensen, JT, 2004. Associations between lying-down behaviour problems and body condition, limb disorders and skin lesions of lactating sows housed in farrowing crates in commercial sow herds. Livestock Production Science 87, 179-187.

Bouten, C.V., Oomens, C.W., Baaijens, F.P., Bader, D.L., 2003. The etiology of pressure ulcers: Skin deep or muscle bound? Archives of Physical Medicine and Rehabilitation 84, 616-619. 
Chen, H.-H., Lin, J.-H., Fung, H.-P., Ho, L.-L., Yang, P.-C., Lee, W.-C., Lee, Y.-P., Chu, R.M., 2003. Serum acute phase proteins and swine health status. The Canadian Journal of Veterinary Research 67, 283-290.

Chen, D.C., Nommsen-Rivers, L., Dewey, K.G., Lönnerdal, B., 1998. Stress during labor and delivery and early lactation performance. The American Journal of Clinical Nutrition 68, 335-344.

EMEA, 1996. The European Agency for the Evaluation of Medicinal Products Veterinary Medicines Evaluation Unit Committee for Veterinary Medicina Products, Ketoprofen (Extension to Pigs) Summary Report. EMEA/MRL/076/96FINAL March 1996

Fosse, T.K., Horsberg, T.E., Haga, H.A., Hormazabal, V., Ranheim, B., 2011a Enantioselective pharmacokinetics of ketoprofen in piglets: The significance of neonatal age. Journal of Veterinary Pharmacology and Therapeutics 34, 153 159.

Fosse, T.K., Toutain, P.-L., Spadavecchia, C., Haga, H.A., Horsberg, T.E., Ranheim, B., 2011b. Ketoprofen in piglets: Enantioselective pharmacokinetics, pharmacodynamics and PK/PD modelling. Journal of Veterinary Pharmacology and Therapeutics 34, 338-349.

Gorecki, C., Lamping, D.L., Brown, J.M., Madill, A., Firth, J., Nixon, J., 2010. Development of a conceptual framework of health-related quality of life pressure ulcers: A patient-focused approach. International Journal of Nursing Studies. 47, 1525-1534.

Guillemet, R., Hamard, A., Quesnel, H., Père, M.C., Etienne, M., Dourmad, J.Y. Meunier-Salau, M.C., 2007. Dietary fibre for gestating sows: Effects on parturition progress, behaviour, litter and sow performance. Animal 1,872880.

Heinonen, M., Orro, T., Kokkonen, T., Munsterhjelm, C., Peltoniemi, O., Valros, A. 2010. Tail biting induces a strong acute phase response and tail-end inflammation in finishing pigs. The Veterinary Journal 184, 303-307.

Heinonen, M., Oravainen, J., Orro, T., Seppä-Lassila, L., Ala-Kurikka, E., Virolainen, J.A., Tast, A., Peltoniemi, O.A.T., 2006. Lameness and fertility of sows and gilts in randomly selected loose-housed herds in Finland. Veterinary Record 159, 383 387.

Jensen, H.E., 2009. Investigation into the pathology of shoulder ulcerations in sows. Veterinary Record 165, 171-174.

Khalif, I.L., Quigley, E.M.M., Konovitch, E.A., Maximova, I.D., 2005. Alterations in the colonic flora and intestinal permeability and evidence of immune activation in chronic constipation. Digestive and Liver Disease 37, 838-849.

Krabbe, K.S., Bruunsgaard, H., Hansen, C.M., Møller, K., Fonsmark, L., Qvist, J. Madsen, P.L., Kronberg, G., Andersen, H.Ø., Skinhøj, P., Pedersen, B.K., 2001 Aging is associated with a prolonged fever response in human endotoxemia. Clinical and Diagnostic Laboratory Immunology 8, 333-338.

Loening-Baucke, V., Swidsinski, A., 2007. Constipation as cause of acute abdominal pain in children. Journal of Pediatrics 151, 666-669.

Maes, D.G.D., Janssens, G.P.J., Delputte, P., Lammertyn, A., de Kruif, A., 2004. Backfat measurements in sows from three commercial pig herds: Relationship with reproductive efficiency and correlation with visual body condition scores. Livestock Production Science 91, 57-67.

Mainau, E., Ruiz-de-la-Torre1, J.L., Dalmau, A., Salleras, J.M., Manteca, X., 2012 Effects of meloxicam $\left(\right.$ Metacam ${ }^{\circledR}$ ) on post-farrowing sow behaviour and piglet performance. Animal 6, 494-501.

Makimura, S., Suzuki, N., 1982. Quantitative determination of bovine serum haptoglobin and its elevation in some inflammatory diseases. Journal of Veterinary Medical Science 44, 15-21.

McGlone, J.J., Nicholson, R.I., Hellman, J.M., Herzog, D.N., 1993. The development of pain in young pigs associated with castration and attempts to prevent castration-induced behavioral changes. Journal of Animal Science 71, 14411446.

Mustonen, K., Ala-Kurikka, E., Orro, T., Peltoniemi, O., Raekallio, M., Vainio, O., Heinonen, M., 2011. Oral ketoprofen is effective in the treatment of noninfectious lameness in sows. The Veterinary Journal 190, 55-59.
Mustonen, K., Niemi, A., Raekallio, M., Heinonen, M., Peltoniemi, O.A., Palviainen, M., Siven, M., Peltoniemi, M., Vaino, O., 2012. Enantiospecific ketoprofen concentrations in plasma after oral and intramuscular administration in growing pigs. Acta Veterinaria Scandinavica 54, 55. http://dx.doi.org/10.1186/ 1751-0147-54-55.

Nathwani, R.A., Pais, S., Reynolds, T.B., Kaplowitz, N., 2005. Serum alanine aminotransferase in skeletal muscle diseases. Hepatology 41, 380-382.

Neirinckx, E., Croubels, S., Remon, J.P., Devreese, M., De Backer, P., Vervaet, C., 2011. Chiral inversion of $\mathrm{R}(-)$ to $\mathrm{S}(+)$ ketoprofen in pigs. The Veterinary Journal 190, 290-292.

Nogueira, R.H.G., Guedes, R.M.C., Souza, J.C.A., 2000. Serum concentrations of creatinine kinase and of triglycerides during lactation in gilts bred older and in multiparous sows fed ad libitum. Arquivo Brasileiro de Medicina Veterinária e Zootecnia 52, 65-67.

Oliviero, C., Heinonen, M., Valros, A., Peltoniemi, O., 2010. Environmental and sowrelated factors affecting the duration of farrowing. Animal Reproduction Science 119, 85-91.

Oravainen, J., Heinonen, M., Seppä-Lassila, L., Orro, T., Tast, A., Virolainen, J.V., Peltoniemi, O.A.T., 2006. Factors affecting fertility in loosely housed sows and gilts: Vulvar discharge syndrome, environment and acute-phase proteins. Reproduction in Domestic Animals 41, 549-554.

Papadopoulos, G.A., Maes, D.G.D., Van Weyenberg, S., van Kempen, T.A.T.G., Buyse, J., Geert, P.J., Janssens, G.P.J., 2009. Peripartal feeding strategy with different n6:n-3 ratios in sows: Effects on sows' performance, inflammatory and periparturient metabolic parameters. British Journal of Nutrition 101, 348-357.

Pyörälä, S., Laurila, T., Lehtonen, S., Leppä, S., Kaartinen, L., 1999. Local tissue damage in cows after intramuscular administration of preparations containing phenylbutazone, flunixin, ketoprofen and metamizole. Acta Veterinaria Scandinavica 40, 145-150.

Raekallio, M.R., Mustonen, K.M., Heinonen, M.L., Peltoniemi, O.A.T., Säkkinen, M.S. Peltoniemi, S.M., Honkavaara, J.M., Vainio, O.M., 2008. Evaluation of bioequivalence after oral, intramuscular, and intravenous administration of racemic ketoprofen in pigs. American Journal of Veterinary Research 69, 108113.

Rolandsdotter, E., Westin, R., Algers, B., 2009. Maximum lying bout duration affects the occurrence of shoulder lesions in sows. Acta Veterinaria Scandinavica 51, 44.

Swinkels, J.M., Pijpers, A., Vernooy, J.C.M., van Nes, A., Verheijden, J.H.M., 1994. Effects of ketoprofen And flunixin in pigs experimentally infected with Actinobacillus pleuropneumoniae. Journal of Veterinary Pharmacology and Therapeutics 17, 299-303.

Tantasuparuk, W., Dalin, A.-M., Lundeheim, L., Kunavongkrit, A., Einarsson, S., 2001. Bodyweight loss during lactation and its influence on weaning-to-service interval and ovulation rate in Landrace and Yorkshire sows in the tropical environment of Thailand. Animal Reproduction Science 65, 273-281.

Valros, A.E., Rundgren, M., Šinka, M., Saloniemi, H., Rydhmer, L., Algers, B., 2002. Nursing behaviour of sows during 5 weeks lactation and effects on piglet growth. Applied Animal Behaviour Science 76, 93-104.

Valros, A., Rundgren, M., Špinka, M., Saloniemi, H., Rydhmer, L., Hultén, F., UvnäsMoberg, K., Tománek, M., Krejcí, P., Algers, B., 2003. Metabolic state of the sow, nursing behavior and milk production. Livestock Production Science 79, 155167.

Verheyen, A.J.M., Maes, D.G.D., Mateusen, B., Deprez, P., Janssen, G.P.J., de Lange, L., Counotte, G., 2007. Serum biochemical reference values for gestating and lactating sows. The Veterinary Journal 174, 92-98.

Weary, D.M., Huzzey, J.M., von Keyserlingk, M.A.G., 2008. Using behavior to predict and identify ill health in animals. Journal of Animal Science 87, 770-777. 